\title{
Renal Cell Carcinoma in Tuberous Sclerosis Complex
}

Ping Yang, M.D., Ph.D. ${ }^{*}, 1,2$, Kristine M. Cornejo, M.D. ${ }^{*}, 1$, Peter M. Sadow, M.D., Ph.D. ${ }^{1}$, Liang Cheng, M.D., Ph.D. ${ }^{3}$, Mingsheng Wang, M.D. ${ }^{3}$, Yu Xiao, M.D. ${ }^{4}$, Zhong Jiang, M.D. ${ }^{5}$, Esther Oliva, M.D. ${ }^{1}$, Sergiusz Jozwiak, M.D., Ph.D. ${ }^{6}$, Robert L. Nussbaum, M.D. ${ }^{7}$, Adam S. Feldman, M.D., MPH ${ }^{8}$, Elahna Paul, M.D., Ph.D. ${ }^{9}$, Elizabeth A. Thiele, M.D., Ph.D. ${ }^{9}$, Jane J. Yu, Ph.D. ${ }^{10}$, Elizabeth P. Henske, M.D. ${ }^{10}$, David J. Kwiatkowski, M.D., Ph.D. ${ }^{10}$, Robert H. Young, M.D. ${ }^{1}$, and Chin-Lee Wu, M.D., Ph.D. ${ }^{1,8}$

${ }^{1}$ Department of Pathology, Massachusetts General Hospital, Harvard Medical School, Boston, MA ${ }^{2}$ Department of Pathology, Sun Yat-sen University Cancer Center, Guangzhou, P.R. China ${ }^{3}$ Department of Pathology and Laboratory Medicine, Indiana University School of Medicine, Indianapolis, IN ${ }^{4}$ Department of Pathology, Peking Union Medical College Hospital, Peking Union Medical College \& Chinese Academy of Medical Sciences, Beijing, P.R. China ${ }^{5}$ Department of Pathology, University of Massachusetts Medical School, Worcester, MA ${ }^{6}$ Department of Neurology and Epileptology, The Children's Memorial Health Institute, Warsaw, Poland ${ }^{7}$ Division of Genomic Medicine, Department of Medicine, and Institute for Human Genetics, University of California, San Francisco ${ }^{8}$ Department of Urology, Massachusetts General Hospital, Harvard Medical School, Boston, MA ${ }^{9} \mathrm{Carol}$ and James Herscot Center for Tuberous Sclerosis Complex, Massachusetts General Hospital, Boston, MA ${ }^{10}$ Division of Translational Medicine, Brigham and Women's Hospital, Harvard Medical School, Boston, MA

\section{Abstract}

Renal cell carcinoma (RCC) occurs in $2-4 \%$ of patients with tuberous sclerosis complex (TSC). Previous reports have noted a variety of histologic appearances in these cancers, but the full spectrum of morphologic and molecular features has not been fully elucidated. We encountered 46 renal epithelial neoplasms from 19 TSC patients and analyzed their clinical, pathological and molecular features, enabling separation of these 46 tumors into three groups. The largest subset of tumors $(n=24)$ had a distinct morphological, immunological and molecular profile, including prominent papillary architecture and uniformly deficient SDHB expression prompting the novel term "TSC-associated papillary RCC." The second group $(\mathrm{n}=15)$ was morphologically similar to a hybrid oncocytic/chromophobe tumor (HOCT) while the last 7 renal epithelial neoplasms of group 3 remained unclassifiable. The TSC-associated papillary RCCs (PRCC) had prominent papillary architecture lined by clear cells with delicate eosinophilic cytoplasmic thread-like strands that occasionally appeared more prominent and aggregated to form eosinophilic globules. All 24 $(100 \%)$ of these tumors were the International Society of Urological Pathology (ISUP) nucleolar

Correspondence: Chin-Lee Wu, M.D., Ph.D., Massachusetts General Hospital, Department of Pathology, Warren Building 225, 55 Fruit Street, Boston, MA 02114, Phone: 617-726-8454, Fax: 617-726-7474, cwu2@ partners.org.

These authors contributed equally to this work.

Conflicts of Interest: The authors have disclosed that they have no significant relationships with, or financial interest in, any commercial companies pertaining to this article. 
grade 2 or 3 with mostly basally located nuclei. Tumor cells from 17 of 24 TSC-associated PRCC showed strong, diffuse labeling for CA-IX (100\%), CK7 (94\%), vimentin (88\%), CD10 (83\%), and were uniformly negative for succinate dehydrogenase subunit B (SDHB), TFE3 and AMACR. Gains of chromosomes 7 and 17 were found in 2 tumors, whereas chromosome $3 p$ deletion and TFE3 translocations were not detected. In this study, we reported a sizable cohort of renal tumors seen in TSC and were able to identify them as different morphotypes which may help to expand the morphologic spectrum of TSC-associated RCC.

\section{Keywords}

Renal cell carcinoma; tuberous sclerosis complex; succinate dehydrogenase; hybrid oncocytic/ chromophobe tumor; immunohistochemistry; molecular genetics

\section{Introduction}

Tuberous sclerosis complex (TSC) is an autosomal dominant genetic disorder. Once characterized by epilepsy, developmental delay and facial angiofibromas, the syndrome can affect nearly every organ system to varying degrees, including the brain, skin, heart, lungs, and kidneys. The incidence of TSC is estimated to be 1 in 6000 to 1 in 10000 persons worldwide.(1) A disease-causing mutation in either TSC1 (Chromosome 9q34), encoding the protein hamartin, or in TSC2 (chromosome 16p13), encoding the protein tuberin, can be identified in most patients with TSC. These proteins act together as tumor suppressors and are components of the mTOR (mammalian target of rapamycin) signaling pathway.(2)

The kidney is affected in approximately $80-85 \%$ of individuals with TSC and renal involvement has been reported as the leading cause of death in TSC patients.(1,3) Renal manifestations in TSC include angiomyolipoma (AML), simple and complex cysts and renal epithelial neoplasms, including oncocytoma and renal cell carcinoma (RCC). With the increasing awareness and surveillance, RCCs are more commonly reported, both in adults and children with TSC. An estimated incidence of RCC in TSC patients is reported to be $2-4 \%$, higher than the estimated incidence in the general population (4), and often occurs in children and young adults. $(5,6)$

A variety of histologies of TSC-associated RCCs have been reported, including clear cell, papillary, chromophobe and unclassified RCC, as well as benign renal oncocytoma.(5, 7-11) However, the full spectrum of morphologic features has not yet been well elucidated due to limited amounts of pathologic material in some cases, and overlapping features with fat-poor angiomyolipomas. Furthermore, the immunophenotype of TSC-associated RCC has not been studied using modern antibody repertoires. (5, 11-13) Few RCCs in TSC patients have been reported to have co-expression of renal tubular and melanocytic markers such as HMB-45, and unlikely represented Xp11 translocation RCC, which further added to the tumor heterogeneity identified in these patients $(5,14)$. Absence of von Hippel-Lindau $(V H L)$ gene mutation and loss of heterozygosity (LOH) was reported in 6 clear cell TSCassociated RCCs (13), in contrast to cytogenetic findings in sporadic RCC of the general non-TSC population, suggesting that clear cell TSC-associated RCC develops independently of canonical pathways. 
To better understand and characterize TSC-associated RCCs, we have studied 46 renal epithelial tumors from 19 TSC patients. We performed immunohistochemical and cytogenetic analysis, and describe the morphological findings among this group of tumors. We sought to investigate whether any particular histologic type of renal cell neoplasm was more frequently found in TSC, and whether any distinct histologic features correlated with genetic abnormalities and/or immunoprofiles. We found that a sizeable subset of TSCassociated renal tumors in this series, 39 of $46(85 \%)$, seen in 17 of 19 (90\%) TSC patients, had distinct features as described below.

\section{Materials and Methods}

\section{Patient and Tumor Specimens}

All 19 patients were treated at the authors' institutions with a clinical diagnosis of TSC as defined by the 1998 Tuberous Sclerosis Complex Consensus Conference.(15, 16)

Tumors were provided by the Massachusetts General Hospital, Boston, MA (n=9), Brigham and Women's Hospital, Boston, MA ( $\mathrm{n}=5)$, University of Massachusetts Medical School, Worcester, MA ( $n=1)$, University of Michigan Health System, Ann Arbor, MI ( $n=1)$, University of California, San Francisco, CA ( $\mathrm{n}=1)$, Children's Memorial Hospital, Warsaw, Poland ( $\mathrm{n}=1)$, and Peking Union Medical College Hospital, Beijing, China $(\mathrm{n}=1)$. The original pathologists varied in their interpretation of the histological findings: 1 was considered to be oncocytoma, 3 were considered to be papillary RCC (one type 1 and two type 2), 5 were considered to be clear cell RCC, 5 were considered to be chromophobe RCC, and 32 were considered to be RCC, unclassified.

The patient demographics, clinical history, and follow-up details were obtained from clinical records. This study was approved by the human study committees at each hospital. The gross findings, including the number and size of the tumors, and laterality, were noted from the pathology reports. All 46 tumors assessed here were formalin-fixed and paraffinembedded. Four $\mu \mathrm{m}$ sections of each tumor with accessible tissue were obtained for hematoxylin and eosin stain, immunohistochemistry and FISH analysis. Histologic subtypes of RCCs were reviewed and reclassified according to criteria proposed in the 2004 World Health Organization (WHO) classification of neoplasms of the kidney and International Society of Urological Pathology Vancouver Classification of Renal Neoplasia (17) and evaluated for the International Society of Urological Pathology (ISUP) nucleolar grade.(18) The tumors that morphologically did not fit the criteria for the usual common renal cell neoplasms were initially assigned the designation of unclassified RCC, according to the above mentioned classification system. Attempts were made later to group such tumors into more definitive categories if any consistent morphologic and/or immunohistochemical features were observed.

\section{Immunohistochemistry}

At least 1 formalin-fixed, paraffin-embedded tissue block from each available tumor was selected for immunohistochemical analysis. Multiple markers beneficial in discriminating different subtypes of RCC were used: CK7 (Dako, Carpinteria, CA; clone OV-TL 12/30; 1:3 
dilution); CA-IX (Novus Biologicals, Littleton, CO; Clone 2D3; 1:5000 dilution); CD10 (Leica, Buffalo Grove, IL; clone 56C6; prediluted); AMACR/P504S (Dako; Clone 13H4; 1:300 dilution); RCC Ma (Dako; clone 5PM314; 1:50 dilution); CD117 (Cell Marque, Rocklin, CA; clone YR145; prediluted); PAX8 (Cell Marque; rabbit polyclonal; 1:50 dilution); HMB45 (Leica; clone HMB45; prediluted); vimentin (Leica; clone SRL33; prediluted); SDHB (Abcam Inc, Cambridge, MA; clone 21A11AE7; 1:1000 dilution), TFE3 (Cell Marque; clone MRQ-37; prediluted).

Immunohistochemistry was performed using the Leica Bond platform (Leica, Buffalo Grove, IL, USA). Sections were deparaffinized on the automated stainer using Bond Dewax Solution (Leica) and rehydrated through graded ethanol solutions to distilled water. Antigen retrieval was achieved by heating sections in Citrate Based Solution ( $\mathrm{pH}$ 6.0, Leica) for CK7, CA-IX, and HMB45, or EDTA Based Solution (pH 9.0, Leica) for TFE3, AMACR, CD10, vimentin, CD117, PAX8, and SDHB. Bound antibodies were localized using Polymer Refine Kit (Leica, Buffalo Grove, IL), or Ultra Vision LP Detection System HRP Polymer (Thermo Scientific, Fremont, CA). Diaminobenzidine (3, 3'-diaminobenzidine) was used as the chromogen and hematoxylin was used as a counterstain. Positive and negative controls were stained concurrently and showed appropriate immunostaining.

The extent of immunohistochemical staining was evaluated microscopically. The percentage of tumor cells showing a positive reaction was estimated and, when appropriate, the staining pattern was documented (membranous, cytoplasmic, apical, granular cytoplasmic, etc.). The interpretation of immunoreactivity for TFE3 and SDHB were evaluated as previously described.(19-22) SDHB stain was considered negative when all tumor cells showed diffuse negative staining compared to the adjacent, normal renal tubular cells showing strong positive staining. SDHB immunohistochemistry was applied on tumors with multiple blocks to confirm the negative results presented in the representative section. SDHB immunohistochemistry was repeated when tumor cells showed negative labeling in the absence of adjacent normal kidney parenchyma (internal positive control). SDHB immunohistochemistry was also performed on a limited number of cases of clear cell, papillary and chromophobe RCC under the same conditions and were used as positive controls. Other stains were graded as negative ( $0 \%$ cells positive), $-/+(1 \%-25 \%),+$ (26\%-50\%), ++ (51\%-75\%), +++ (76\%-100\%).

\section{Hale staining}

Hale colloidal iron staining (Muller-Mowry modification) was performed in all HOTC cases. The staining pattern was evaluated as negative, diffuse cytoplasmic or apical.

\section{Fluorescence In Situ Hybridization}

For patients with available tissue, at least 1 formalin-fixed, paraffin-embedded tissue block was selected for fluorescence in situ hybridization (FISH).

FISH analyses were performed as described previously.(22-24) Briefly, a hematoxylin and eosin-stained slide from each block was examined to identify areas containing tumor cell clusters for cell counting. Multiple tissue sections $4 \mu \mathrm{m}$ in thickness were prepared from formalin-fixed paraffin-embedded tissue blocks. The slides were deparaffinized with 2 
washes of xylene, 15 minutes each, and subsequently washed twice with absolute ethanol, 10 minutes each, and then air dried in a fume hood. Next, the slides were treated with $0.1 \mathrm{mM}$ citric acid (pH 6.0) (Zymed, South San Francisco, CA) at $95{ }^{\circ} \mathrm{C}$ for 10 minutes, rinsed in distilled water for 3 minutes, followed by a wash of $2 \times$ standard saline citrate (SSC) for 5 minutes. Digestion of the tissue was performed by applying $0.4 \mathrm{~mL}$ of pepsin $(5 \mathrm{mg} / \mathrm{mL}$ in $0.1 \mathrm{~N} \mathrm{HCl} / 0.9 \mathrm{NaCl}$ ) (Sigma, St Louis, MO) at $37^{\circ} \mathrm{C}$ for 40 minutes. The slides were rinsed with distilled water for 3 minutes, washed with $2 \times \mathrm{SSC}$ for 5 minutes, and air dried.

Centromeric chromosome enumeration probes (CEP) were utilized for chromosome 3 (CEP3, Orange), chromosome 7 (CEP7, Green), and chromosome 17 (CEP17, Orange) from Vysis (Downers Grove, IL). FISH for chromosomes 7 and 17 was performed with centromeric a-satellite DNA probe cocktail containing CEP7 and CEP17. Deletion of chromosome $3 p$ was assessed using a probe cocktail containing centromeric a-satellite DNA probes for CEP3 (Spectrum Orange) and the subtelomeric probe for 3p25 (3pTel25, Spectrum Green, Vysis). Assessment of TFE3 translocation was using an Interphase Breakapart FISH assay with the 2 DNA probes.(22) Probes CEP7-CEP17 were diluted with tDenHyb1 in a ratio of 1:100 and probes CEP3-3p25, TFE were diluted with $t$ DenHyb 2 (Insitus, Albuquerque, NM) in a ratio of $1: 100$ and $1: 25$, respectively. The diluted probe (5 $\mu \mathrm{L})$ was applied to each slide in reduced light conditions. The slides were then covered with a $22 \times 22-m m$ cover slip and sealed with rubber cement. Denaturation was achieved by incubating the slides at $83{ }^{\circ} \mathrm{C}$ for 12 minutes in a humidified box and hybridization at $37^{\circ} \mathrm{C}$ overnight. The cover slips were removed, and the slides were washed twice with $0.1 \times \mathrm{SSC} /$ $1.5 \mathrm{M}$ urea at $45^{\circ} \mathrm{C}$ (20 minutes for each), followed by a wash with $2 \times \mathrm{SSC}$ for 20 minutes, and with $2 \times \mathrm{SSC} / 0.1 \% \mathrm{NP}-40$ for 10 minutes at $45^{\circ} \mathrm{C}$. The slides were further washed with $2 \times \mathrm{SSC}$ at room temperature for 5 minutes. The slides were air dried and counterstained with 10mL 4, 6-diamidino-2-phenylindole (Insitus, Albuquerque, NM), covered with cover slips, and sealed with nail polish.

\section{FISH Evaluation}

The slides were examined using a Zeiss Axioplan 2 microscope (Zeiss, Gottingen, Germany) with the following filters (Chroma, Brattleboro, VT): SP-100 for DAPI, FITC MF-101 for Spectrum Green, and Gold 31003 for Spectrum Orange. The images were acquired with a charged coupled device camera and analyzed with MetaSystem Isis Software (MetaSystem, Belmont, MA). Four sequential focus stacks with $0.4 \mu \mathrm{m}$ intervals were acquired and then integrated into a single image to reduce thickness-related artifacts.

The method of analysis was partially described previously.(22, 25) In brief, for each slide, a minimum of 100 tumor cell nuclei were examined under fluorescence microscopy at 1000x magnification. Only nonoverlapping tumor nuclei were evaluated. Non-neoplastic renal cortex was examined as an internal control. Definitions of chromosomal trisomy of chromosomes 7 and 17 were based on the Gausian model and were related to the nonneoplastic controls. The cutoff values for each probe were set at mean plus 3 SDs (mean +3 SD) of the control values. $(26,27)$ The cutoff value for $3 p$ deletion was defined as a $3 p 25 /$ CEP3 ratio of $₫ 0.7$, as previously described. $(24,28,29)$ A TFE3 fusion result was reported 
when $\geq 10 \%$ of the tumor nuclei showed the split-signal pattern, based on other commercially available break-apart FISH assays and TFE3 break-apart FISH assays.(30)

\section{Results}

The clinicopathologic characteristics of 46 TSC-associated RCCs are summarized in Table 1. There was a predominance of female patients (male-to-female ratio 1:2). Mean age at the first diagnosis of a renal tumor was 30 years (range from 7-59 y). Three patients underwent biopsy, two chose conservative management, and one declined surgical intervention and has since died. Four patients underwent radical nephrectomy and 12 had partial nephrectomy. Follow-up data was available for 14 of 19 (74\%) patients with a mean follow-up period of 48 months (range from 3-147 mo). One patient had regional lymph node metastasis at presentation (patient 6); she has remained free of distant metastasis but has since developed new bilateral renal neoplasms in her most recent surveillance imaging. All other treated patients are alive with neither recurrence nor metastasis.

The average tumor size was $2.9 \mathrm{~cm}$ (range $0.1-22 \mathrm{~cm}$ ). Fourt-eight percent of the tumors were ISUP grade 2, while ISUP grade 1, 3 and 4 were $6 \%, 44 \%$ and 2\%, respectively. Eight of the 19 patients (42\%) had multiple renal tumors (2-15) and 5 of 19 patients (26\%) had bilateral neoplasms. Of 5 patients with bilateral tumors, 2 had synchronous bilateral lesions and 3 had their contralateral tumor(s) diagnosed 1, 5 and 11 years after the initial nephrectomies. Concurrent, multiple renal angiomyolipomas, microscopic or macroscopic, were found adjacent to the tumors in $56 \%$ of patients and cystic changes were observed in $56 \%$ of tumors.

The gross tumor appearance from 14 of 17 patients by partial or radical nephrectomy was noted to be well-circumscribed, and occasionally cystic. Eight tumors were described as encapsulated. The cut surface varied and was described as yellow, tan, red-brown, hemorrhagic, or variegated. No gross tumor necrosis was reported.

The combined morphologic, immunohistochemical, and cytogenetic approaches allowed us to subclassify these 46 tumors into three groups. The largest subset of tumors comprised of 24 neoplasms, and was termed TSC-associated papillary RCC. The second group contained 15 renal tumors morphologically similar to a hybrid oncocytic/chromophobe tumor (HOCT). The last group of 7 renal epithelial neoplasms remained unclassifiable (Table 2).

\section{TSC-associated Papillary RCC}

Ninety-one percent of 24 group one tumors were microscopically circumscribed by fibrous stroma of variable thickness. On low power, a complex branching papillary architecture was observed in $75 \%$ of the tumors (18/24) (Figure 1A, 1C and 2A). In the remaining 6 tumors, papillary architecture was present focally, appearing as small blunt papillae tufting into the lumen (Figure 4E). One of these tumors (patient 7, tumor 12) exhibited an overwhelmingly nested growth pattern (Figure 4A-4C), whereas 5 others, all from patient 8 , showed a primarily solid growth pattern (Figure 4D-F). Patient 8 had 10 additional predominantly papillary tumors, similar to those displayed in Figures 1 and 2. These 15 tumors from patient 8 showed several growth patterns (solid, compact nested or papillary) that merged with each 
other (Figure 4D-E). Cystic change was commonly present (13/24), usually as microcysts (Figure 1E). The cells lining the cysts were morphologically similar to those in the rest of the tumor. Other architectural patterns, including acinar, tubular, and alveolar patterns, were observed in varying proportions.

Cytologically, all except one tumor were predominantly composed of large clear cells with voluminous cytoplasm. Cells with finely granular, eosinophilic cytoplasm were focally present in 14 of 24 tumors. Tumor cells with clear cytoplasm were admixed with tumor cells with eosinophilic cytoplasm without forming large geographic aggregates of one cell type (Figure 1F). On high power, the clear cytoplasm often contained delicate thread-like eosinophilic strands that occasionally appeared more prominent and aggregated to form eosinophilic globules, a unique and consistent finding in all 24 of the tumors (Figure 1B, 1D, 2B, 4C and 4F). Cell borders were largely discrete, especially in clear cell areas, irrespective of the architecture. Fifty-four percent of the tumors were ISUP grade 2, and the remaining $46 \%$ of tumors were ISUP grade 3 . The nucleus was round to oval to mildly irregular, positioned either basally or centrally. Nuclear morphology was quite homogeneous in clear cells but larger nuclei with prominent nucleoli were easily identified in cells with eosinophilic cytoplasm. Mitotic figures were rare. Psammoma bodies/ calcifications were absent from all tumors. Foamy histiocytes were occasionally present in cyst fluid, but not in the core of the papillae.

All tumor parenchyma were surrounded by hyalinized stroma, which sometimes showed myxoid change (Figure 1E, 2A and 4D). Focal hemorrhage and necrosis occurred in one tumor removed shortly after embolization treatment (patient 7, tumor 12).

Only patient 6 had pathologically confirmed metastasis to 3 of 8 peri-aortic lymph nodes (the largest metastatic node was $1.3 \mathrm{~cm}$ ) that were resected synchronously with the kidney tumor. The morphologic features of the nodal metastasis resembled the kidney tumor.

Seventeen of 24 group 1 renal tumors had adequate tissue for immunohistochemical analyses. Results of immunohistochemistry evaluation are displayed in Table 3. SDHB protein expression was absent in all 17 tumors studied (Figure 2F, 3A-F, 4I). Negative SDHB labeling was interpreted only when the tumor cells showed diffuse negative staining and the adjacent normal renal tubular cells showed positive granular cytoplasmic staining. CK7 expression was strongly and diffusely positive in almost all tumors (17/18) (Figure 2C, 4G) and all CK7-expressing tumors exhibited predominantly papillary growth. The only tumor (tumor 12) showing focal CK7 expression (5\%) was composed of nested clear to eosinophilic cells with rare papillary structures (Figure 4A-C). Unlike sporadic papillary RCC, these TSC-associated tumors completely lacked staining for AMACR. CA-IX membranous staining was diffusely positive in all tumors, resembling clear cell RCC (Figure 2D, 4H). CD10 staining was positive in all cases, mostly strong, and diffuse (Figure 2E), although weak and/or focal positivity for CD10 was seen in three tumors displaying a primarily solid growth (patient 8 ). Vimentin and PAX8 were consistently positive in a majority of tumors (15/17 and 15/15, respectively). All tumors studied were negative for TFE3, HMB45, RCC Marker and CD117. 
In summary, tumors within this group showed an immunoprofile distinctly different from any existing renal neoplasm subtype, which is summarized as: SDHB-/TFE3-/ RCC Ma-/ vimentin++/ CK7++/AMACR-/CA-IX++/CD10++.

FFPE blocks from 16 of these group 1 tumors were sectioned and analyzed by FISH, as summarized in Table 3. None of the 16 tumors showed evidence of chromosome 3p deletion. Two neoplasms (tumor 12 and 28) showed gains of chromosomes 7 and 17. None of the tumors showed evidence of a TFE3 gene fusion by break-apart FISH assay.

\section{Hybrid Oncocytic/Chromophobe Tumor (HOCT)}

Fifteen of the 46 (33\%) renal epithelial neoplasms displayed morphologic characteristics of both an oncocytoma and chromophobe RCC, albeit in varying amounts, similar to a hybrid oncocytic/chromophobe tumor (HOCT). There were two main histologic patterns identified in these neoplasms. The first pattern, displayed in 5 of 15 (33\%) HOCT tumors, was comprised of polygonal tumor cells with abundant eosinophilic cytoplasm and centrally placed, round nuclei, resembling an oncocytoma, with perinuclear cytoplasmic clearing or halos, similar to chromophobe RCC (tumor 7, 9, 36, 42, 45) (Figure 5A-B). The second contained a mosaic pattern, identified in 5 of $15(33 \%)$ HOCT tumors, in which there was admixing of areas with features characteristic of oncocytoma and chromophobe RCC (tumor $29,30,35,43,44$ ) (Figure 5C), respectively. The 5 remaining tumors that did not exhibit either of the two predominant histologic patterns, demonstrated various combinations of morphologic features of the two neoplasms. Four of the 5 tumors contained a nested and tubular architecture with cells comprised of abundant eosinophilic cytoplasm typical of an oncocytoma with more irregular, folded or raisinoid nuclei, a quality of chromophobe RCC (Figure 5D) (tumor 1, 37, 39, 41, 46).

The immunoprofile and FISH results of the tumors from this group are reported in Table 3. In general, the tumors were reactive for PAX8, CD117 and CD10, and negative for TFE3, HMB45, and CA-IX. Immunostaining with vimentin, RCC and AMACR were variable. All of the tumors had preserved SDHB immunoreactivity. None of the tumors revealed aberrations in chromosomes 3p, 7, or 17. In addition, a TFE3 translocation was not observed in any of the tumors.

\section{Unclassified RCC}

A small subset of RCCs $(n=7)$ contained morphologic and/or architectural patterns that did not readily fit into any of the World Health Organization classification of RCC subtypes. Therefore, they were categorized as unclassified RCCs (Figure 6).

Tumors 4, 5 and 6 from patient 4 displayed a variety of morphologies. Tumor 4 contained tubules and papillae lined by cells with abundant eosinophilic cytoplasm with centrally placed round nuclei and prominent nucleoli intermixed with moderate amounts of inflammatory infiltrate (Figure 6A). Immunohistochemically, it was positive for vimentin, RCC Ma, CD10 and AMACR, and negative for CK7, CA-IX and CD117. Tumor 5 contained a papillary architecture lined by a single layer of cuboidal cells with clear to eosinophilic cytoplasm, and small round nuclei (Figure 6B). Immunohistochemically it was positive for vimentin, RCC Ma, CK7 and AMACR and negative for CD10, CA-IX and 
CD117. Tumor 6 contained a papillary architecture lined by both clear to eosinophilic cytoplasm and round nuclei (Figure 6C) with an immunoprofile that was positive for vimentin, RCC Ma, and AMACR and negative for CK7, CD10, CA-IX and CD117.

Both tumors 32 (Figure 6E) and 34 (Figure 6F) from patient 11 were well- circumscribed and composed of cuboidal cells with densely eosinophilic cytoplasm and oval to mildly irregular nuclei. The neoplastic cells were arranged in either compact nests or small tubules. Foamy macrophages were commonly seen in the lumen of the tubules or within the stroma. The immunoprofiles of these two tumors were: vimentin-/RCC-/CK7-/CD10+/CA-IX-/ AMACR++/PAX8-.

Tumor 33 (Figure 6D) also from patient 11 was well-circumscribed, composed of sheets of cells with fluffy eosinophilic cytoplasm and small uniform nuclei with inconspicuous nucleoli. The tumor cells only showed diffuse positive immunoreactivity for CA-IX and were negative for all the other markers in the immunohistochemical panel.

Tumor 40 (Figure 6G-I) from patient 17 was composed of cuboidal cells with indistinct cell borders, arranged in compact nests and separated by abundant sinusoidal vasculature. The cytoplasm was oncocytic with a granular and vacuolated quality. Nuclei were centrally placed, round to oval in shape and displayed finely granular chromatin and small nucleoli. The immunohistochemical profiles and morphologic features of these neoplasms did not readily fit into any of the WHO renal cell carcinoma classifications.

Material was available for immunohistochemistry from 7 and FISH from 6 of the tumors in this group. Results are summarized in Table 3. In brief, all tumors were negative for TFE3 and HMB45. Preservation of SDHB by immunohistochemistry was also present. Immunohistochemical staining for the other markers showed variable patterns. There were no aberrations identified in chromosomes 3p, 7 or 17. Additionally, no TFE3 gene fusions were detected.

\section{Discussion}

Whereas most renal cell carcinomas (RCCs) occur sporadically, 3-5\% are associated with hereditary syndromes. To date, there are 10 well-defined hereditary renal cancer (HRC) syndromes, including Von-Hippel Lindau (VHL) disease, hereditary papillary RCC, hereditary leiomyomatosis-RCC, Birt-Hogg-Dubé (BHD) syndrome, and tuberous sclerosis complex (TSC), among others.(31) Homogenous tumors are seen in some RCC syndromes, such as clear cell RCC in VHL disease and type 1 papillary RCC in hereditary papillary RCC. Heterogeneous tumors are reported in BHD syndrome.

Renal cell carcinoma is a rare renal manifestation in TSC patients, with an estimated incidence of 2-4\%, which is nonetheless higher than in the general population.(4) Although renal carcinomas have been increasingly found in TSC patients, their histological and molecular characteristics remained poorly defined. The reported histological appearance of TSC-associated RCCs is heterogeneous. Most have been identified as clear cell RCCs, but other reported types include papillary, chromophobe, and unclassified RCC as well as benign renal oncocytoma. $(5,7-11)$ 
In this study, we first describe 24 renal epithelial neoplasms from 9 TSC patients for their morphological, immunophenotypic and cytogenetic features. Morphologically, these tumors displayed a prominent papillary architecture lined predominantly by cells with clear cytoplasm. Prominent complex, branching papillary structures are a hallmark of these tumors. Another unique feature is the delicate eosinophilic cytoplasmic thread-like strands, not seen in other types of RCC. Immunologically, all studied neoplasms were consistently positive for CK7, vimentin, CD10 and carbonic anhydrase IX (CA-IX), with no immunoreactivity for SDHB, TFE3, AMACR, and RCC Marker. This immunological profile is distinct from all other known RCC subtypes.

Each of the four known RCC subtypes--clear cell RCC, type 1 papillary RCC, Xp11 translocation RCC, clear cell (tubulo) papillary RCC--share some morphological and immunological features with the TSC-associated papillary RCC (Table 4).

For example, all the TSC-associated PRCCs consistently displayed reactivity to vimentin, CD10, PAX8, CA-IX, and were negative for AMACR, which is a typical immunohistochemical profile of clear cell RCC. But the TSC-associated tumors were also diffusely and strongly positive for CK7 and uniformly negative for SDHB, distinguishing them from clear cell RCC. In addition, the diffuse membranous staining for CA-IX among these tumors presumably reflecting activation of the hypoxia-inducible factor (HIF) pathway, was similar to sporadic clear cell RCC; however, no deletion of chromosome 3p, where the $V H L$ gene resides, was detected in any neoplasms examined. Duff $\mathrm{K}$ et al. similarly found neither $V H L$ loss of heterozygosity nor other $V H L$ gene mutation in any of their six clear cell RCC tumors from TSC patients.(13) Together these findings indicate that this novel tumor subset is distinct from sporadic clear cell RCC and may implicate a novel mechanism to activate the HIF pathway in renal cell carcinogenesis in the setting of TSC.

Xp11 translocation RCC is another renal tumor in the differential diagnosis. This neoplasm is typically composed of cells with voluminous clear to faintly eosinophilic cytoplasm, arranged in papillary and nested structures. Nuclear labeling for TFE3 protein by immunohistochemistry is a characteristic feature of Xp11 translocation carcinoma and was not identified in any of the neoplasm in our series. This observation was further validated by break-apart TFE3 FISH assay which showed no TFE3 gene translocation in these tumors. (32) In contrary to the high nuclear grade in Xp11 translocation RCC, most tumors in our series were intermediate nuclear grade. Psammoma bodies that are common in Xp11 translocation RCC were also not seen in any of these TSC-associated tumors.

A recently emerged entity, clear cell (tubulo) papillary RCC (CCPRCC), is recognized and classified within the International Society of Urological Pathology Vancouver Classification of Renal Neoplasia.(17) One of the characteristic features of CCPRCC is the apical positioning of the low grade nuclei away from the basement membrane, arranged in a linear fashion, which was only focally present in two tumors in our study. The CCPRCC specific cup-shaped expression pattern of CA-IX, was not identified in any of our samples. Instead, CA-IX was diffusely and circumferentially expressed along the cell membrane in all tumors, resembling clear cell RCC. Furthermore, CD10 staining was diffusely positive in almost all tumors, different from its negative to variable staining in CCPRCC. 
Papillary RCC (PRCC) tumor cells contain a small amount of clear to slightly eosinophilic cytoplasm. The abundant clear cell cytoplasm seen in the TSC-associated papillary RCC tumors is uncommon in PRCC. While clear cell changes and fine cytoplasmic granulations can be occasionally seen in PRCC, these changes usually appear adjacent to hemosiderin deposition and/or necrosis, associated with global degenerative changes.(33) Psammoma bodies and foamy histiocytes in the fibrovascular cores, common features in PRCC, were not seen in any of these TSC-associated tumors. Although TSC-associated papillary RCC tumors were positive for CK7, similar to PRCC, CA-IX was also diffusely and strongly positive, unlike typical PRCC, and AMACR expression was uniformly absent. Even though 2 tumors within this group showed gains of chromosomes 7 and 17, the typical immunohistochemical profile of PRCC (positive for both CK7 and AMACR) is not appreciated. The significance of gains of chromosomes 7 and 17 in these two tumors is not understood.

Another interesting finding in this study was that this subset of renal neoplasms uniformly lack expression of SDHB protein by immunohistochemistry. Succinate dehydrogenase (SDH)/ mitochondrial complex II is a key respiratory enzyme, located in the inner mitochondrial membrane that links two important pathways in energy conversion: the Krebs tricarboxylic acid cycle and oxidative phosphorylation. It catalyzes the oxidation of succinate to fumarate and transfers electrons to the respiratory chain ubiquinone pool.(34) Five proteins are involved in SDH complex, SDHA, SDHB, SDHC, SDHD and SDHAF2 and are encoded by five nuclear genes, which together are known $S D H x$ genes/SDH complex genes. SDHA and SDHB form the catalytic core of the enzyme complex.

Inherited or somatic mutation in $S D H x$ genes are well documented and associated with the development of pheochromocytoma/paraganglioma (PHEO/PGL) and less commonly, with gastrointestinal stromal tumors (GISTs). Thus, SDHx genes are regarded as tumor suppressors. Renal cell carcinomas have rarely been reported with germline mutations in SDHB.(19, 35-40), SDHC(41), or SDHD.(38) Together, less than 20 patients with any $S D H x$ gene mutations have been reported thus far, and mostly with a personal and/or family history of PHEO/PGL.

Double hit inactivation of any component of the SDH complex results in degradation of the SDHB subunit. Therefore, immunohistochemistry for SDHB is negative whenever there is mutation/inactivation of $S D H A, S D H B, S D H C, S D H D$, or $S D H A F 2$. Negative staining for SDHB has been quite reliable in identifying germline mutation of the SDH B, C and D subunits in PHEO/PGL.(42, 43) In a few paraganglioma syndrome-associated renal tumors, negative SDHB expression was highly correlated with germline mutations in $S D H B$ and $S D H D$ genes. Notably, none of the TSC patients in our cohort has a personal or family medical history of PHEO/PGL. The absence of a family history does not formally exclude the possibility of paraganglioma syndromes given the age related penetrance of $S D H x$ gene mutation and phenotypic heterogeneity. Nonetheless, our patients all met diagnostic criteria for TSC, and had no features otherwise suggestive of the paraganglioma syndrome.

Renal tumors associated with $S D H x$ mutations from earlier reports were classified as clear cell, chromophobe, papillary, and unclassified RCC, or oncocytoma, without detailed 
description or illustration of morphologic features.(35-38, 44) More recent reports have emphasized the presence of distinctive cytoplasmic inclusions in cuboidal cells with bubbly eosinophilic cytoplasm arranged in solid nests.(17, 19, 40, 45) Importantly, we did not observe these features in any of the SDHB-negative renal tumors reported here. It remains to be determined if the morphological features of the renal tumors seen in these TSC patients are seen only in TSC, or whether they will be also observed in non-TSC patients.

It is known that lack of SDH enzyme activity results in abnormal hypoxia signaling and may trigger tumor formation. Succinate accumulates as a result of SDH dysfunction, which consequently inhibits HIF-a prolyl hydroxylases in the cytosol, leading to stabilization and activation of HIF-1a. HIF-1a induction may then in turn up-regulate multiple downstream genes including CA-IX. This effect may contribute to carcinogenesis in these tumors in the absence of VHL mutation or chromosome 3p loss, and explain the diffuse membranous IHC labeling for CA-IX we observed.

The mechanism of loss of SDH expression in these tumors is unknown. SDHx germline mutation seems quite unlikely since these patients had no features of SDH genetic syndromes, and the co-existence of TSC1 or TSC2 plus SDHx germline gene mutations would be an extremely rare event to recur in this clustered fashion by random chance. One possible mechanism may be the acquisition of somatic mutations that inactivate one or more of the $S D H x$ genes, hence contributing to tumorigenesis. An alternative possibility is that the effects of TSC1/TSC2 loss and mTORC1 activation in the particular renal epithelial cell of origin for these tumors may somehow interrupt normal SDH expression. It will be of interest to see if similar cases are found in sporadic, non-TSC patients, and to examine the molecular pathology of such cases for TSC and $S D H$ gene involvement. If germline $S D H x$ mutation is found in this group of tumors, it poses a possibility that two tumor suppressor genes ( $S D H$ and TSC) may together contribute to one oncogenic event.

In this study, we additionally describe a second distinct morphologic group comprised of 15 renal epithelial neoplasms from 9 TSC patients which have features of a hybrid oncocytic/ chromophobe tumor (HOCT). HOCT tumors are most commonly described in patients with Birt-Hogg Dubé syndrome and renal oncocytosis, with more recent reports of sporadic cases.(46-50) It is hypothesized that renal oncocytoma and chromophobe RCC are the extremes of the same morphologic spectrum as they both originate from the intercalated cells of the renal collecting tubules, giving rise to neoplasms with mixed histology.(46) Although this subset of renal epithelial neoplasms do not have a distinct immunoprofile, their characteristic features may alert the pathologist to the possibility of a TSC-associated renal neoplasm, in addition to those associated with Birt-Hogg Dubé syndrome. Furthermore, correctly diagnosing this neoplasm is important as HOCTs have been identified as a subtype of chromophobe RCC by the International Society of Urological Pathology Vancouver Classification of Renal Neoplasia.(17)

Interestingly, renal tumors with HOCT morphology are identified in both TSC and BirtHogg Dubé syndromes in which mutations in the TSC and folliculin genes, respectively, result in downstream mTOR activation. Therefore, we hypothesize that the tumors associated with these hereditary syndromes may acquire a similar or shared somatic 
mutation or genetic alteration, resulting in their distinct morphology. Further studies using modalities such as genome sequencing may help to elucidate the morphologic link in these two hereditary syndromes.

In conclusion, RCCs in TSC contain distinct morphologic features and include TSCassociated papillary RCC and HOCT. Similar to other well-defined hereditary renal cancer syndromes in which distinct RCC morphologic features are associated with specific mutations, these neoplasms, in addition to angiomyolipomas may help to identify morphologic clues to renal neoplasms associated with TSC.

\section{Acknowledgments}

Source of Funding: This study was supported by National Institutes of Health Grant CA120964.

\section{References}

1. Kwiatkowski, DJ.; WV; Thiele, EA., editors. Tuberous Sclerosis Complex: Genes, Clinical features, and Therapeutics. KGaA, Weinheim: WILEY-VCH verlag GmbH \& Co.; 2010.

2. Narayanan V. Tuberous sclerosis complex: genetics to pathogenesis. Pediatr Neurol. 2003; 29:404409. [PubMed: 14684235]

3. Shepherd CW, Gomez MR, Lie JT, et al. Causes of death in patients with tuberous sclerosis. Mayo Clin Proc. 1991; 66:792-796. [PubMed: 1861550]

4. Ljungberg B, Campbell SC, Choi HY, et al. The epidemiology of renal cell carcinoma. Eur Urol. 2011; 60:615-621. [PubMed: 21741761]

5. Bjornsson J, Short MP, Kwiatkowski DJ, et al. Tuberous sclerosis-associated renal cell carcinoma. Clinical, pathological, and genetic features. Am J Pathol. 1996; 149:1201-1208. [PubMed: 8863669]

6. Washecka R, Hanna M. Malignant renal tumors in tuberous sclerosis. Urology. 1991; 37:340-343. [PubMed: 2014599]

7. Kang SG, Ko YH, Kang SH, et al. Two different renal cell carcinomas and multiple angiomyolipomas in a patient with tuberous sclerosis. Korean J Urol. 2010; 51:729-732. [PubMed: 21031096]

8. Jimenez RE, Eble JN, Reuter VE, et al. Concurrent angiomyolipoma and renal cell neoplasia: a study of 36 cases. Mod Pathol. 2001; 14:157-163. [PubMed: 11266520]

9. Paul E, Thiele EA, Shailam R, et al. Case records of the Massachusetts General Hospital. Case 26-2011. A 7-year-old boy with a complex cyst in the kidney. N Engl J Med. 2011; 365:743-751. [PubMed: 21864169]

10. Kubo M, Iwashita K, Oyachi N, et al. Two different types of infantile renal cell carcinomas associated with tuberous sclerosis. J Pediatr Surg. 2011; 46:E37-41. [PubMed: 22008361]

11. Al-Saleem T, Wessner LL, Scheithauer BW, et al. Malignant tumors of the kidney, brain, and soft tissues in children and young adults with the tuberous sclerosis complex. Cancer. 1998; 83:22082216. [PubMed: 9827727]

12. Schreiner A, Daneshmand S, Bayne A, et al. Distinctive morphology of renal cell carcinomas in tuberous sclerosis. Int J Surg Pathol. 2010; 18:409-418. [PubMed: 19403547]

13. Duffy K, Al-Saleem T, Karbowniczek M, et al. Mutational analysis of the von hippel lindau gene in clear cell renal carcinomas from tuberous sclerosis complex patients. Mod Pathol. 2002; 15:205-210. [PubMed: 11904337]

14. Pea M, Bonetti F, Martignoni G, et al. Apparent renal cell carcinomas in tuberous sclerosis are heterogeneous: the identification of malignant epithelioid angiomyolipoma. Am J Surg Pathol. 1998; 22:180-187. [PubMed: 9500218]

15. Hyman MH, Whittemore VH. National Institutes of Health consensus conference: tuberous sclerosis complex. Arch Neurol. 2000; 57:662-665. [PubMed: 10815131] 
16. Roach ES, Gomez MR, Northrup H. Tuberous sclerosis complex consensus conference: revised clinical diagnostic criteria. J Child Neurol. 1998; 13:624-628. [PubMed: 9881533]

17. Srigley JR, Delahunt B, Eble JN, et al. The International Society of Urological Pathology (ISUP) Vancouver Classification of Renal Neoplasia. Am J Surg Pathol. 2013; 37:1469-1489. [PubMed: 24025519]

18. Delahunt B, Cheville JC, Martignoni G, et al. The International Society of Urological Pathology (ISUP) grading system for renal cell carcinoma and other prognostic parameters. Am J Surg Pathol. 2013; 37:1490-1504. [PubMed: 24025520]

19. Gill AJ, Pachter NS, Chou A, et al. Renal tumors associated with germline SDHB mutation show distinctive morphology. Am J Surg Pathol. 2011; 35:1578-1585. [PubMed: 21934479]

20. Rao Q, Liu B, Cheng L, et al. Renal cell carcinomas with $\mathrm{t}(6 ; 11)(\mathrm{p} 21 ; \mathrm{q} 12)$ : A clinicopathologic study emphasizing unusual morphology, novel alpha-TFEB gene fusion point, immunobiomarkers, and ultrastructural features, as well as detection of the gene fusion by fluorescence in situ hybridization. Am J Surg Pathol. 2012; 36:1327-1338. [PubMed: 22895266]

21. Argani P, Antonescu CR, Illei PB, et al. Primary renal neoplasms with the ASPL-TFE3 gene fusion of alveolar soft part sarcoma: a distinctive tumor entity previously included among renal cell carcinomas of children and adolescents. Am J Pathol. 2001; 159:179-192. [PubMed: 11438465]

22. Rao Q, Williamson SR, Zhang S, et al. TFE3 break-apart FISH has a higher sensitivity for Xp11.2 translocation-associated renal cell carcinoma compared with TFE3 or cathepsin K immunohistochemical staining alone: expanding the morphologic spectrum. Am J Surg Pathol. 2013; 37:804-815. [PubMed: 23598965]

23. Cheng L, MacLennan GT, Zhang S, et al. Evidence for polyclonal origin of multifocal clear cell renal cell carcinoma. Clin Cancer Res. 2008; 14:8087-8093. [PubMed: 19088024]

24. Gobbo S, Eble JN, Maclennan GT, et al. Renal cell carcinomas with papillary architecture and clear cell components: the utility of immunohistochemical and cytogenetical analyses in differential diagnosis. Am J Surg Pathol. 2008; 32:1780-1786. [PubMed: 18779729]

25. Halat S, Eble JN, Grignon DJ, et al. Multilocular cystic renal cell carcinoma is a subtype of clear cell renal cell carcinoma. Mod Pathol. 2010; 23:931-936. [PubMed: 20348877]

26. Jones TD, Eble JN, Wang M, et al. Molecular genetic evidence for the independent origin of multifocal papillary tumors in patients with papillary renal cell carcinomas. Clin Cancer Res. 2005; 11:7226-7233. [PubMed: 16243792]

27. Cossu-Rocca P, Eble JN, Delahunt B, et al. Renal mucinous tubular and spindle carcinoma lacks the gains of chromosomes 7 and 17 and losses of chromosome $\mathrm{Y}$ that are prevalent in papillary renal cell carcinoma. Mod Pathol. 2006; 19:488-493. [PubMed: 16554730]

28. Brunelli M, Fiorentino M, Gobbo S, et al. Many facets of chromosome 3p cytogenetic findings in clear cell renal carcinoma: the need for agreement in assessment FISH analysis to avoid diagnostic errors. Histol Histopathol. 2011; 26:1207-1213. [PubMed: 21751152]

29. Gobbo S, Eble JN, Grignon DJ, et al. Clear cell papillary renal cell carcinoma: a distinct histopathologic and molecular genetic entity. Am J Surg Pathol. 2008; 32:1239-1245. [PubMed: 18594469]

30. Kim SH, Choi Y, Jeong HY, et al. Usefulness of a break-apart FISH assay in the diagnosis of Xp11.2 translocation renal cell carcinoma. Virchows Arch. 2011; 459:299-306. [PubMed: 21773754]

31. Verine J, Pluvinage A, Bousquet G, et al. Hereditary renal cancer syndromes: an update of a systematic review. Eur Urol. 2010; 58:701-710. [PubMed: 20817385]

32. Green WM, Yonescu R, Morsberger L, et al. Utilization of a TFE3 break-apart FISH assay in a renal tumor consultation service. Am J Surg Pathol. 2013; 37:1150-1163. [PubMed: 23715164]

33. Ross H, Martignoni G, Argani P. Renal cell carcinoma with clear cell and papillary features. Arch Pathol Lab Med. 2012; 136:391-399. [PubMed: 22458901]

34. Rustin P, Munnich A, Rotig A. Succinate dehydrogenase and human diseases: new insights into a well-known enzyme. Eur J Hum Genet. 2002; 10:289-291. [PubMed: 12082502] 
35. Vanharanta S, Buchta M, McWhinney SR, et al. Early-onset renal cell carcinoma as a novel extraparaganglial component of SDHB-associated heritable paraganglioma. Am J Hum Genet. 2004; 74:153-159. [PubMed: 14685938]

36. Neumann HP, Pawlu C, Peczkowska M, et al. Distinct clinical features of paraganglioma syndromes associated with SDHB and SDHD gene mutations. JAMA. 2004; 292:943-951. [PubMed: 15328326]

37. Ricketts C, Woodward ER, Killick P, et al. Germline SDHB mutations and familial renal cell carcinoma. J Natl Cancer Inst. 2008; 100:1260-1262. [PubMed: 18728283]

38. Ricketts CJ, Forman JR, Rattenberry E, et al. Tumor risks and genotype-phenotype-proteotype analysis in 358 patients with germline mutations in SDHB and SDHD. Hum Mutat. 2010; 31:4151. [PubMed: 19802898]

39. Srirangalingam U, Walker L, Khoo B, et al. Clinical manifestations of familial paraganglioma and phaeochromocytomas in succinate dehydrogenase B (SDH-B) gene mutation carriers. Clin Endocrinol (Oxf). 2008; 69:587-596. [PubMed: 18419787]

40. Housley SL, Lindsay RS, Young B, et al. Renal carcinoma with giant mitochondria associated with germ-line mutation and somatic loss of the succinate dehydrogenase B gene. Histopathology. 2010; 56:405-408. [PubMed: 20459544]

41. Malinoc A, Sullivan M, Wiech T, et al. Biallelic inactivation of the SDHC gene in renal carcinoma associated with paraganglioma syndrome type 3. Endocr Relat Cancer. 2012; 19:283-290. [PubMed: 22351710]

42. Gill AJ, Benn DE, Chou A, et al. Immunohistochemistry for SDHB triages genetic testing of SDHB, SDHC, and SDHD in paraganglioma-pheochromocytoma syndromes. Hum Pathol. 2010; 41:805-814. [PubMed: 20236688]

43. van Nederveen FH, Gaal J, Favier J, et al. An immunohistochemical procedure to detect patients with paraganglioma and phaeochromocytoma with germline SDHB, SDHC, or SDHD gene mutations: a retrospective and prospective analysis. Lancet Oncol. 2009; 10:764-771. [PubMed: 19576851]

44. Henderson A, Douglas F, Perros P, et al. SDHB-associated renal oncocytoma suggests a broadening of the renal phenotype in hereditary paragangliomatosis. Fam Cancer. 2009; 8:257260. [PubMed: 19184535]

45. Gill AJ, Pachter NS, Clarkson A, et al. Renal tumors and hereditary pheochromocytomaparaganglioma syndrome type 4. N Engl J Med. 2011; 364:885-886. [PubMed: 21366490]

46. Delongchamps NB, Galmiche L, Eiss D, et al. Hybrid tumour 'oncocytoma-chromophobe renal cell carcinoma' of the kidney: a report of seven sporadic cases. BJU international. 2009; 103:1381-1384. [PubMed: 19154497]

47. Pote N, Vieillefond A, Couturier J, et al. Hybrid oncocytic/chromophobe renal cell tumours do not display genomic features of chromophobe renal cell carcinomas. Virchows Arch. 2013; 462:633638. [PubMed: 23708994]

48. Hes O, Petersson F, Kuroda N, et al. Renal hybrid oncocytic/chromophobe tumors - a review. Histol Histopathol. 2013; 28:1257-1264. [PubMed: 23740406]

49. Petersson F, Gatalica Z, Grossmann P, et al. Sporadic hybrid oncocytic/chromophobe tumor of the kidney: a clinicopathologic, histomorphologic, immunohistochemical, ultrastructural, and molecular cytogenetic study of 14 cases. Virchows Arch. 2010; 456:355-365. [PubMed: 20300772]

50. Waldert M, Klatte T, Haitel A, et al. Hybrid renal cell carcinomas containing histopathologic features of chromophobe renal cell carcinomas and oncocytomas have excellent oncologic outcomes. Eur Urol. 2010; 57:661-665. [PubMed: 19477583]

\section{Abbreviations}

$\begin{array}{ll}\text { RCC } & \text { Renal Cell Carcinoma } \\ \text { PRCC } & \text { Papillary RCC }\end{array}$




$\begin{array}{ll}\text { TSC } & \text { Tuberous Sclerosis Complex } \\ \text { HOCT } & \text { hybrid oncocytic/chromophobe tumor } \\ \text { CA-IX } & \text { carbonic anhydrase IX } \\ \text { CK7 } & \text { cytokeratin } 7 \\ \text { SDH } & \text { Succinate dehydrogenase } \\ \text { SDHB } & \text { Succinate dehydrogenase B subunit } \\ \text { AMACR } & \text { a-methylacyl coenzyme A racemase } \\ \text { LOH } & \text { loss of heterozygosity } \\ \text { PHEO } & \text { pheochromocytoma } \\ \text { PGL } & \text { paraganglioma } \\ \text { VHL } & \text { von Hippel-Lindau } \\ \text { BHD } & \text { Birt-Hogg-Dubé } \\ \text { CCPRCC } & \text { clear cell (tubulo) papillary RCC } \\ \text { GISTs } & \text { gastrointestinal stromal tumors }\end{array}$




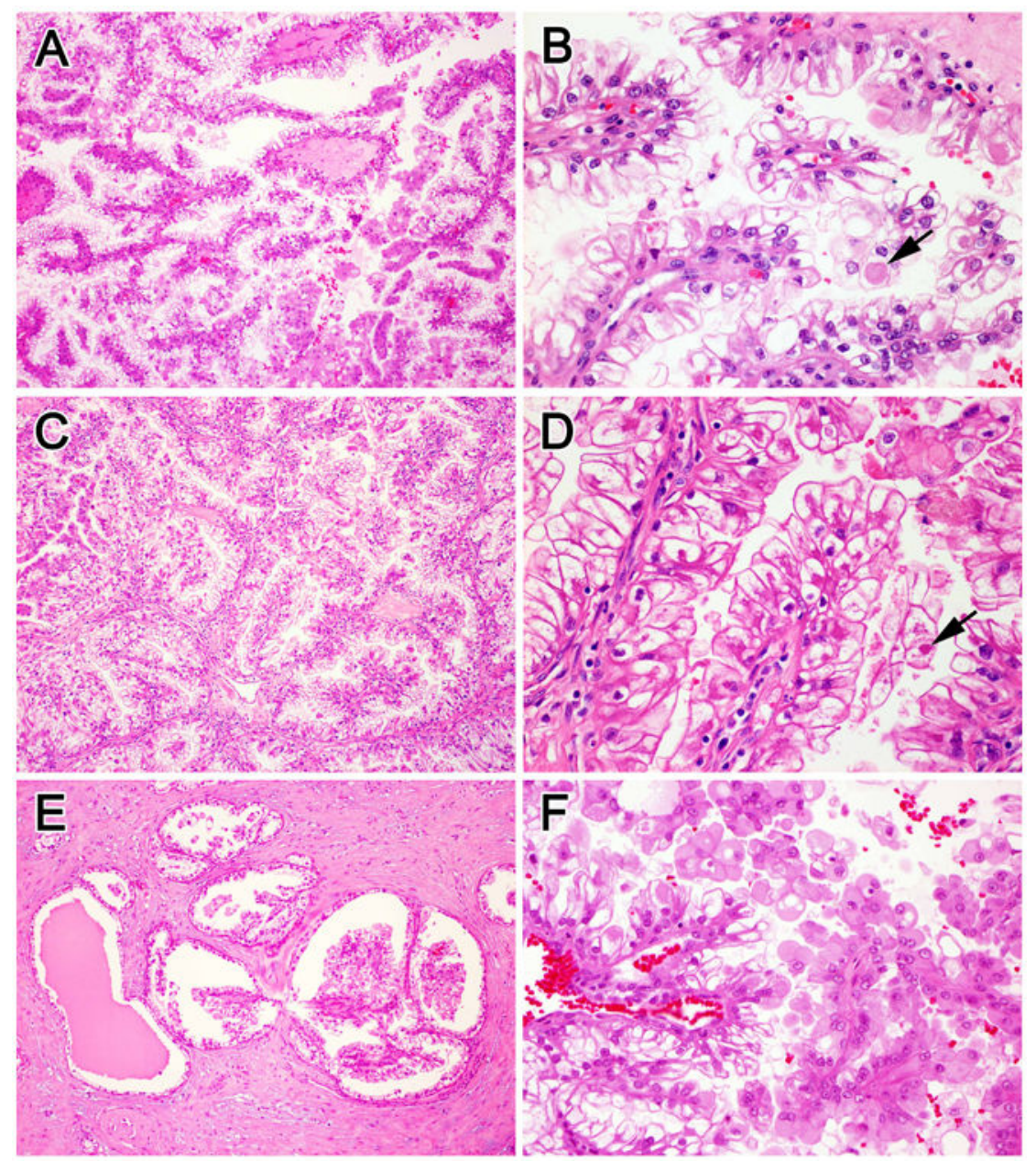

Figure 1.

Morphologic features of TSC-associated - papillary RCC.

A, B (patient 6, tumor 11); C, D (patient 9, tumor 28); E (patient 8, tumor 22); F (patient 6, tumor 10$)$.

A, C: On low power, tumors predominantly displayed complex branching papillary structure; B, D: On high power, the clear cytoplasm often contained delicate thread-like eosinophilic strands which occasionally aggregated to form eosinophilic globules (arrow); E: Fibrotic stroma and cystic changes were common; F: Tumor cells with clear cytoplasm were admixed with tumor cells with fine granular eosinophilic cytoplasm. 

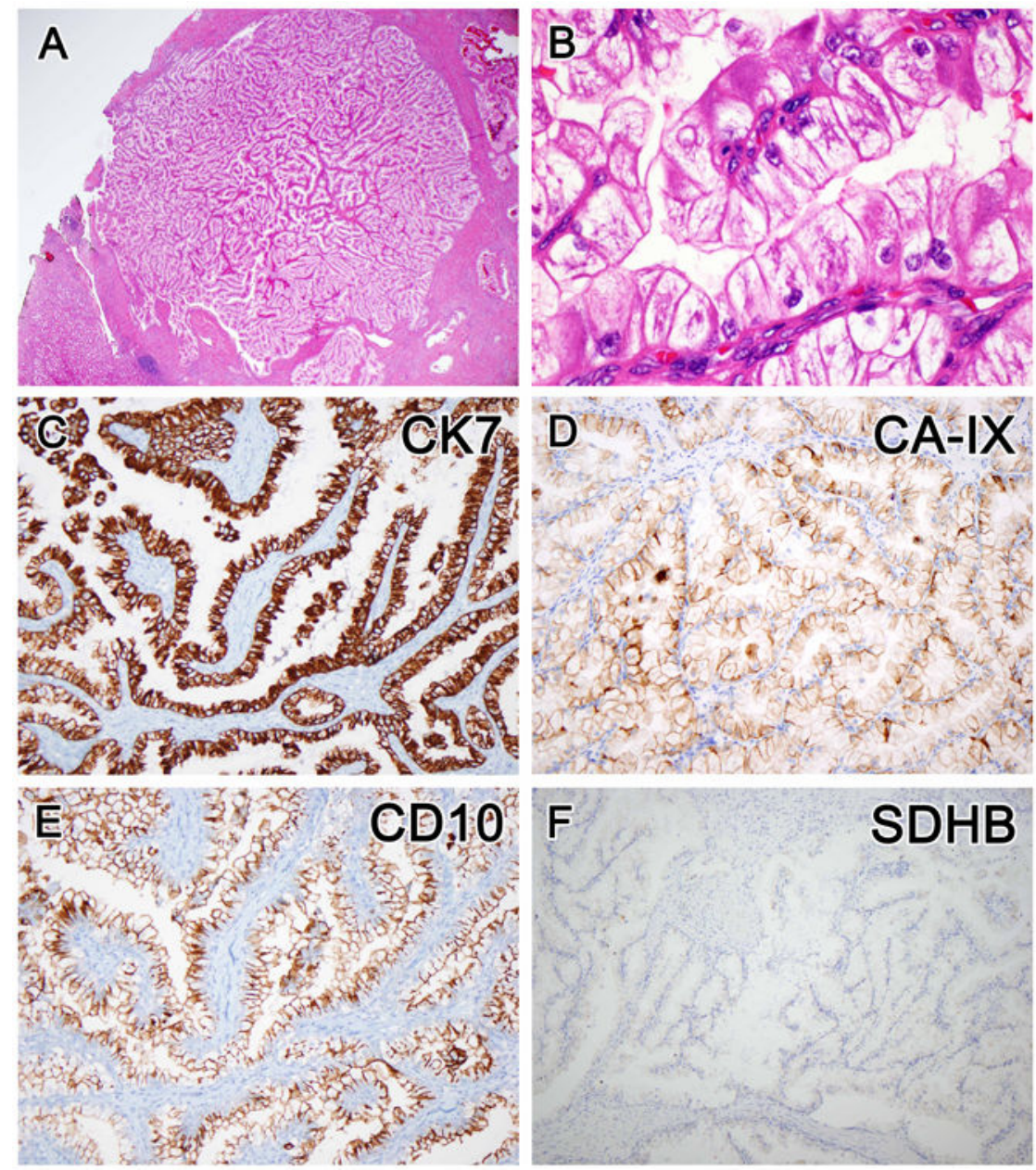

Figure 2.

TSC-associated papillary RCC with prominent papillary structure.

A-F (patient 5, tumor 8)

A: On low power, the main tumor nodule was surrounded by thick fibrous stroma; B: On high power, the papillae were lined by large clear cells with fine eosinophilic cytoplasmic thread-like strands. The nuclei oriented towards the basement membrane; C-F:

Immunohistochemical stains showed that tumor cells were strongly and diffusely positive for CK7, CD10 and CA-IX; and negative for SDHB. 


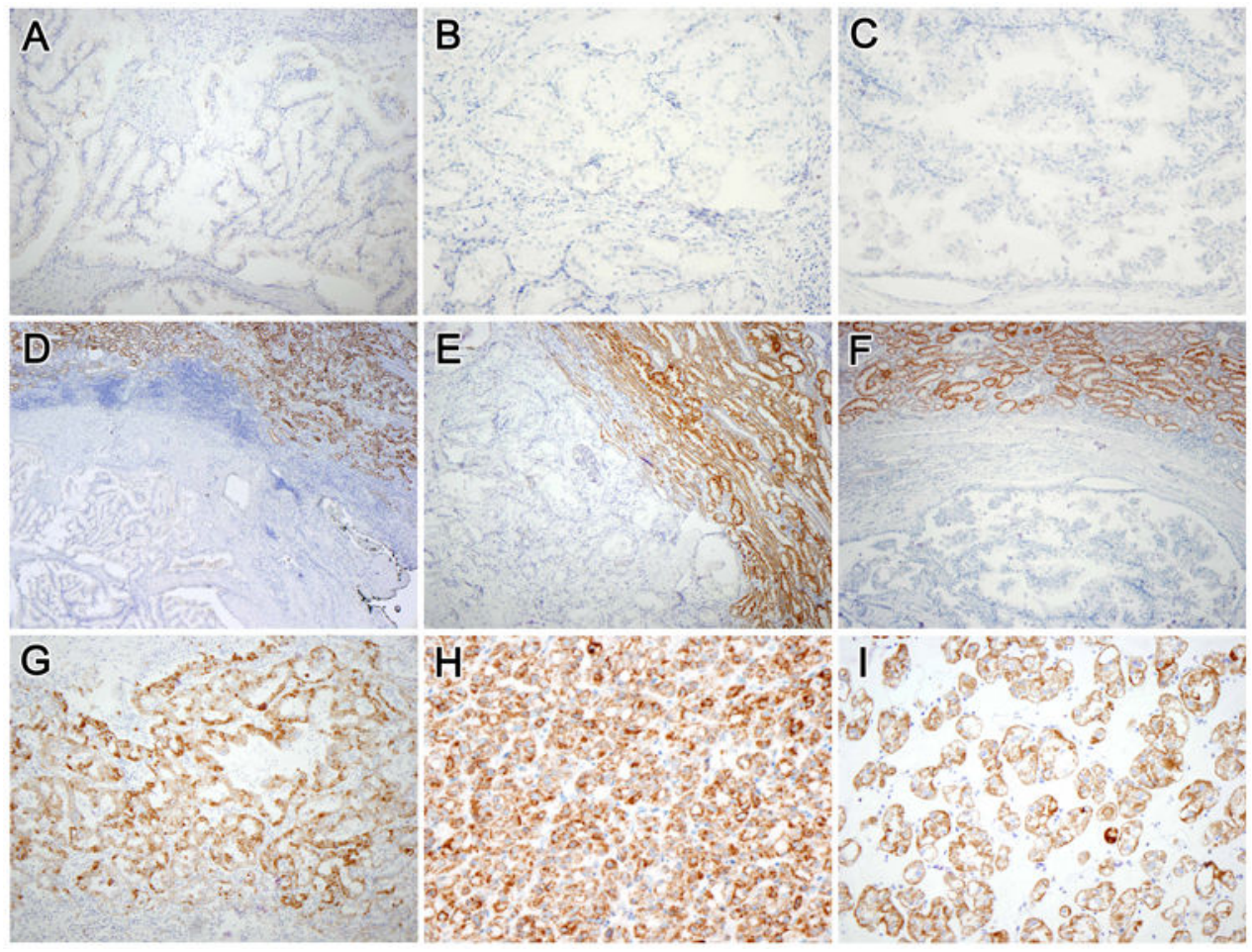

Figure 3.

SDHB immunohistochemical staining.

A, D (patient 5, tumor 8); B, E (patient 8, tumor 27); C, F (patient 8, tumor 24); G-I: Control tumors, $\mathrm{G}$ (patient 4, tumor 4); H (patient 10, tumor 30); I (patient 5, tumor 7).

A-C: Tumor cells from TSC-associated papillary RCC showed completely negative staining for SDHB; D, E, F: Lower magnification of the tumors displayed in A, B, and C, respectively, demonstrated strong granular cytoplasmic staining in adjacent normal renal tubules, serving as an internal positive controls; G-I: Examples of SDHB positive renal epithelial tumors in TSC patients, showing a staining pattern that was both cytoplasmic and distinctly granular representing a mitochondrial pattern, was considered positive. 


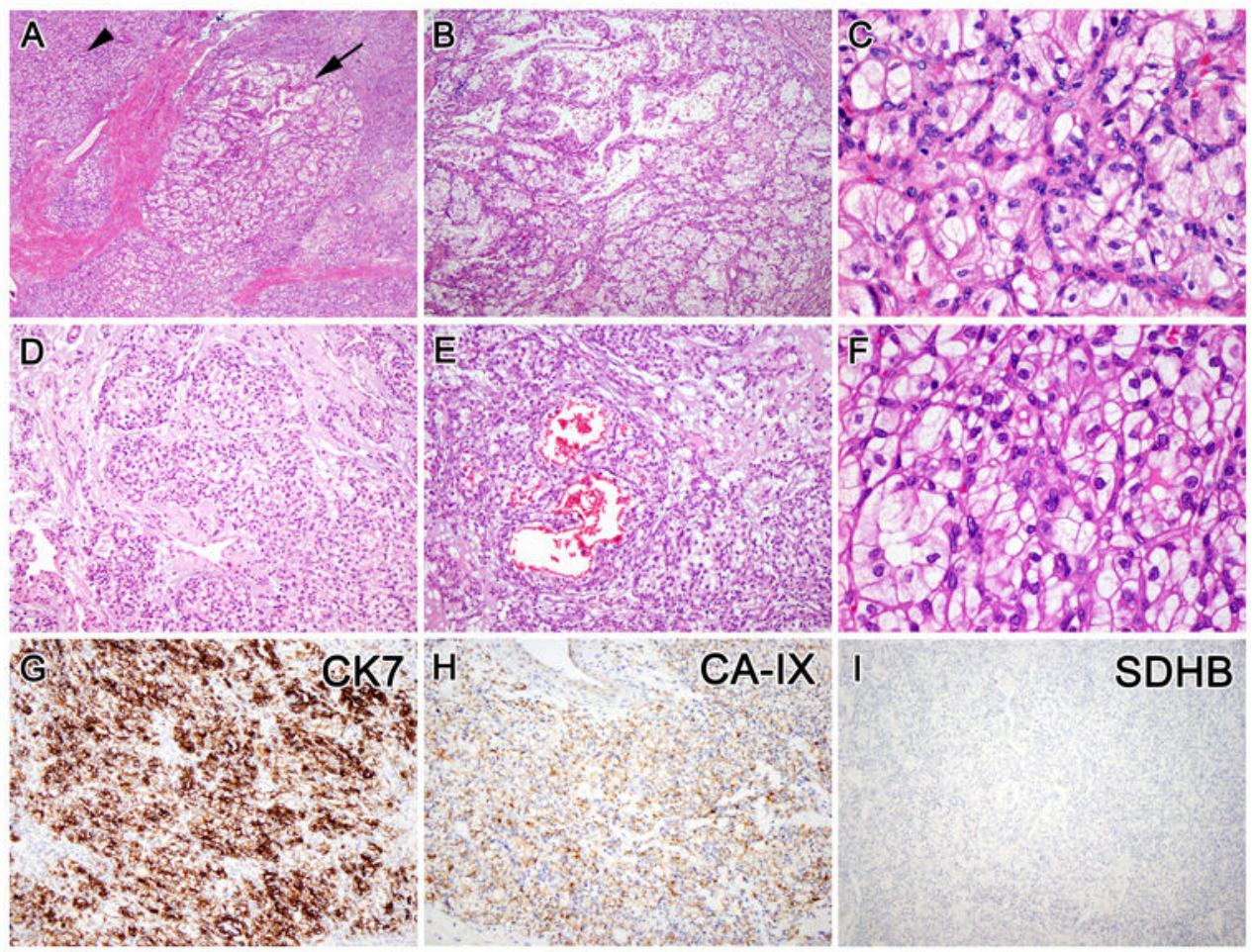

Figure 4.

TSC-associated papillary RCC with prominent compact nested growth pattern showed similar cytological and immunological features.

A-C: (patient 7, tumor 12); D-F: (patient 8, tumor 21); G-I: (patient 8, tumor 21).

A: The only focus of tumor cells exhibiting papillary architecture in background of nested growth; B: Higher magnification of the papillary growth pattern of A (arrow); C: Higher magnification of left upper corner of A (arrowhead), showing the compact nested architecture consisting of clear cells with fine eosinophilic thread-like strands; D: Solid cell nests were surrounded by loose hyalinized stroma; E: Tubules with small blunt papillae tufted into the luminal space; F: On high power, clear cells with eosinophilic strands formed compact nests. G-I: Immunohistochemical stains showed that tumor cells were strongly and diffusely positive for CK7 and CA-IX, and negative for SDHB. 


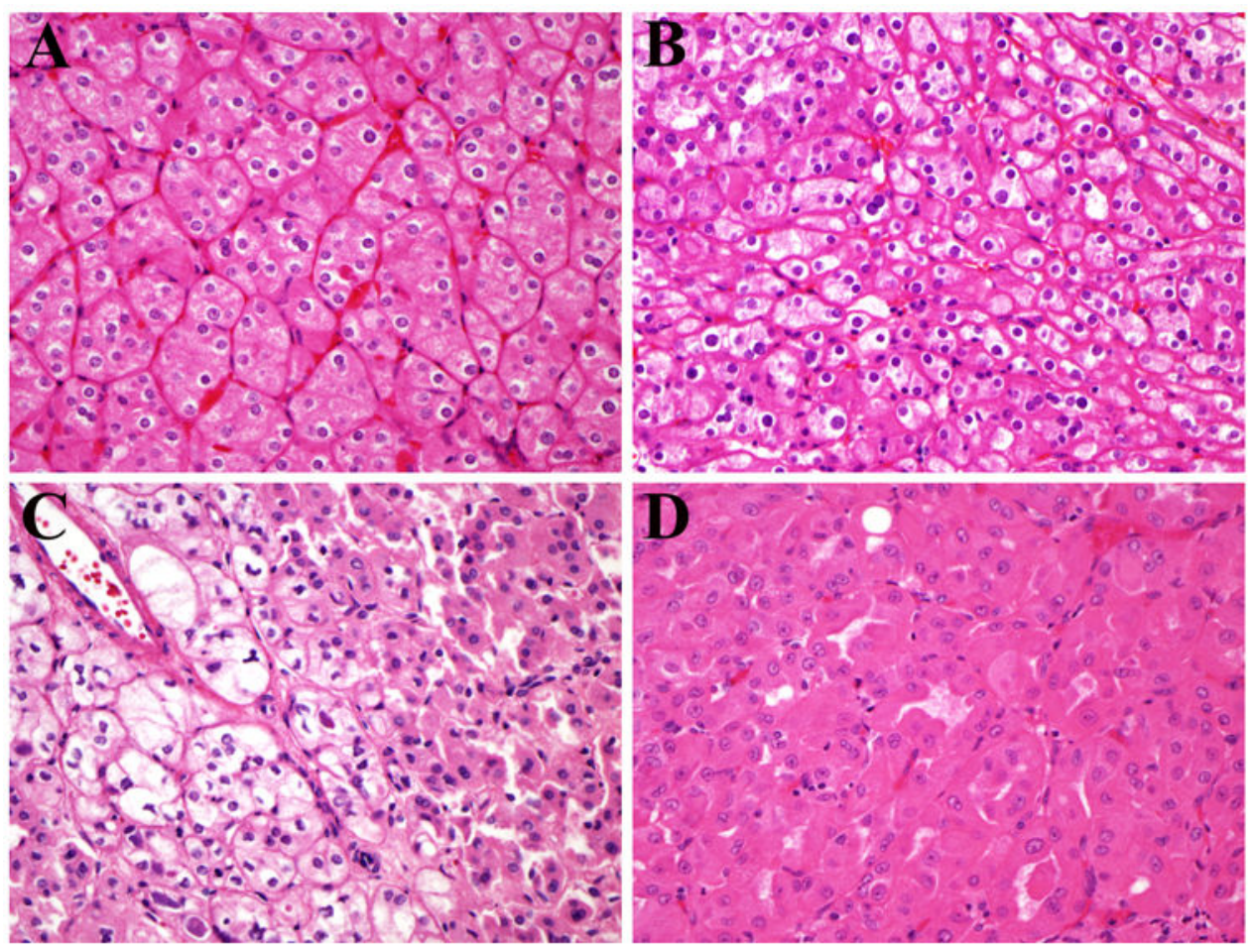

Figure 5.

Histologic features of hybrid oncocytic/chromophobe tumors (HOCTs).

A: (patient 18, tumor 45); B: (patient 5, tumor 7); C: (patient 12, tumor 35); D: (patient 18, tumor 46).

A, B: Pattern 1 with polygonal tumor cells containing abundant eosinophilic cytoplasm and centrally placed, round nuclei with perinuclear clearing; C: Pattern 2 with mosaicism of areas with features characteristic of oncocytoma and chromophobe RCC. D: Nested and tubular architecture with cells comprised of abundant eosinophilic cytoplasm typical of an oncocytoma with more irregular, folded nuclei. 

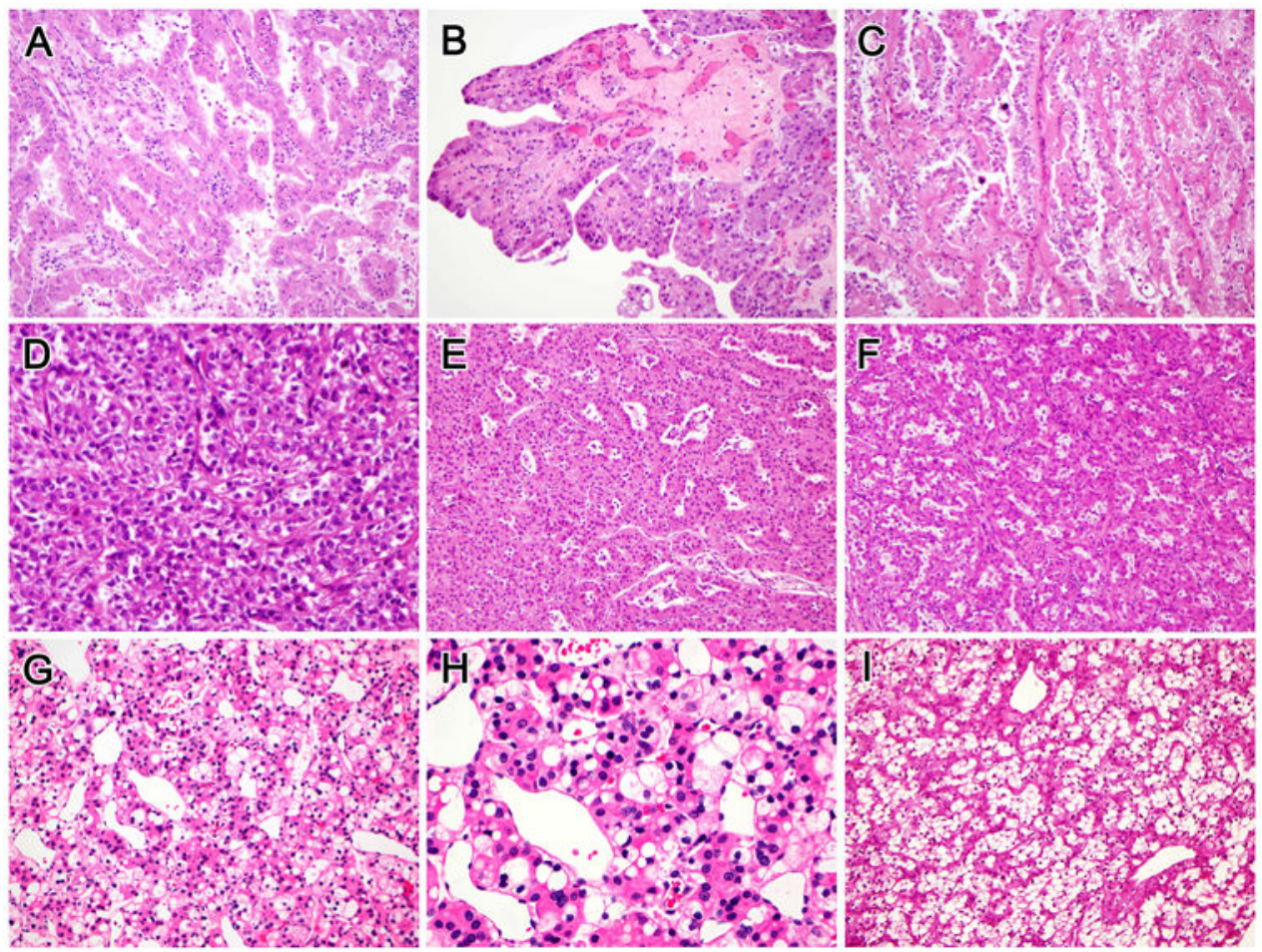

Figure 6.

TSC-associated renal tumors with unusual features remain unclassified.

A-C: (patient 4, tumor 4, 5, 6); D-F: (patient 11, tumor 33, 32, 34); G-I: (patient 17, tumor 40). 


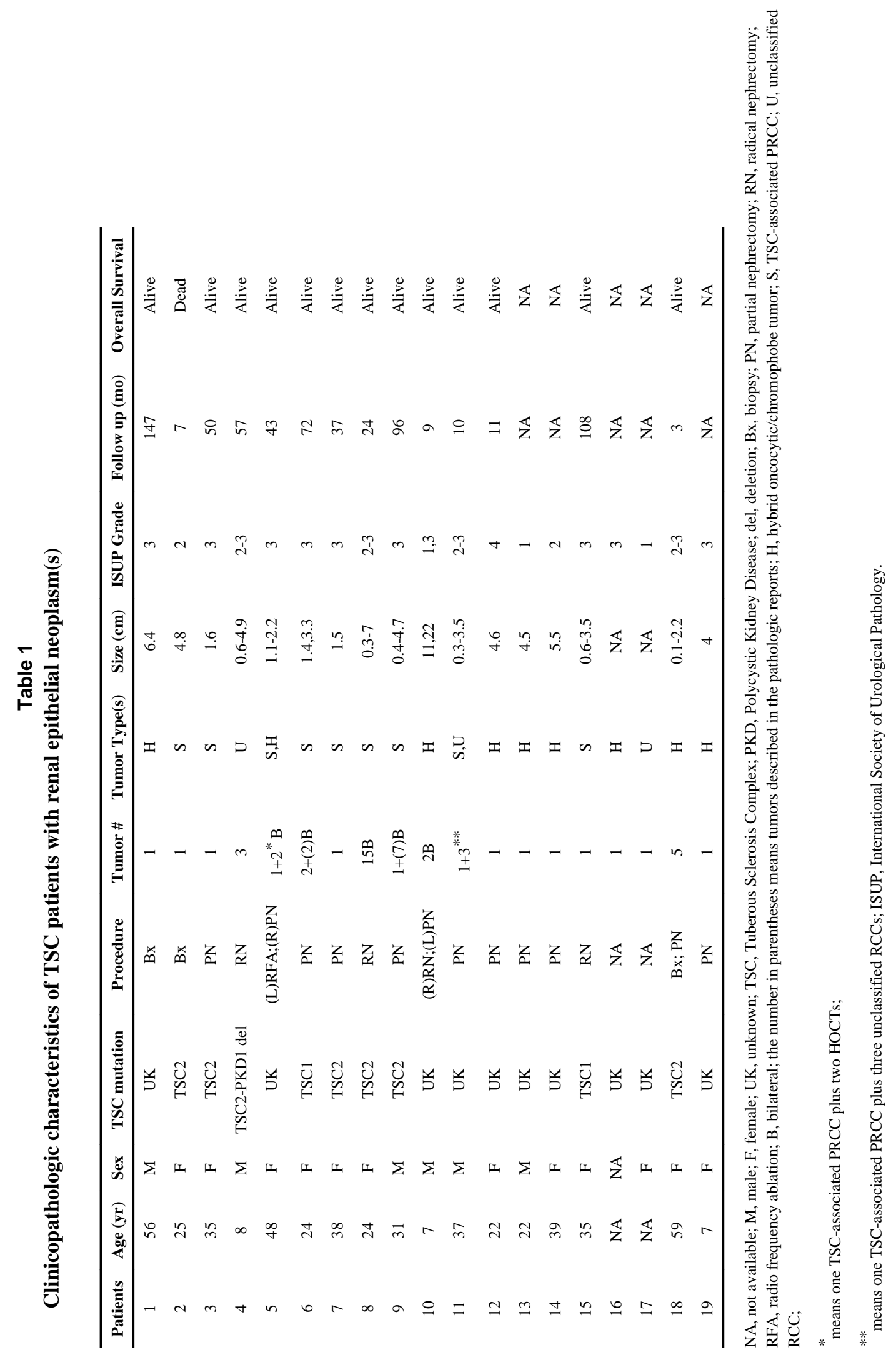

Am J Surg Pathol. Author manuscript; available in PMC 2015 July 01. 
Table 2

Distribution by Histologic Subtypes

\begin{tabular}{lcc}
\hline Tumor & \# of tumor & \# of patient \\
\hline TSC-associated Papillary RCC & 24 & 9 \\
Hybrid oncocytic chromophobe tumor (HOCT) & 15 & 9 \\
Unclassified RCC & 7 & 3 \\
\hline
\end{tabular}




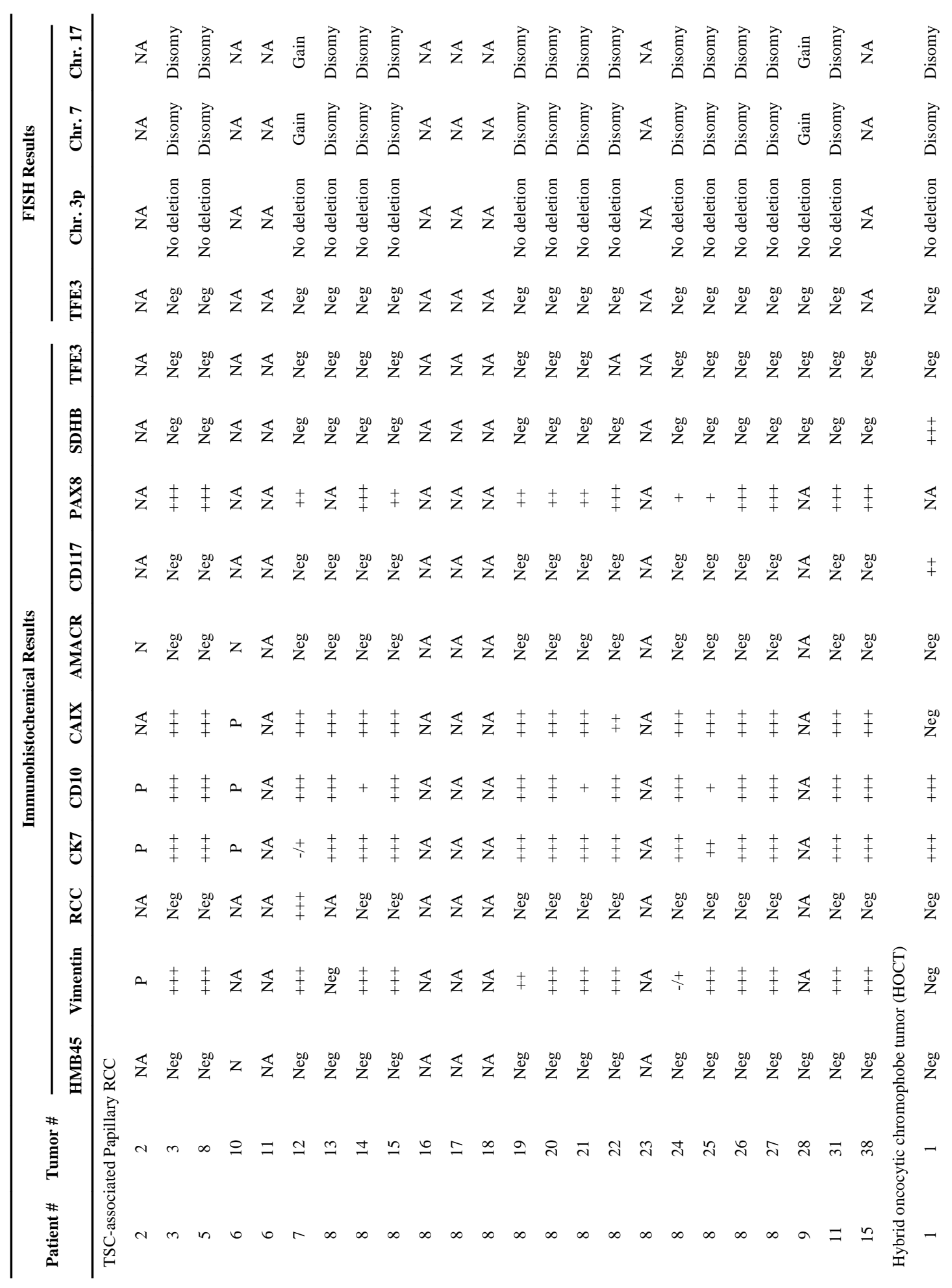




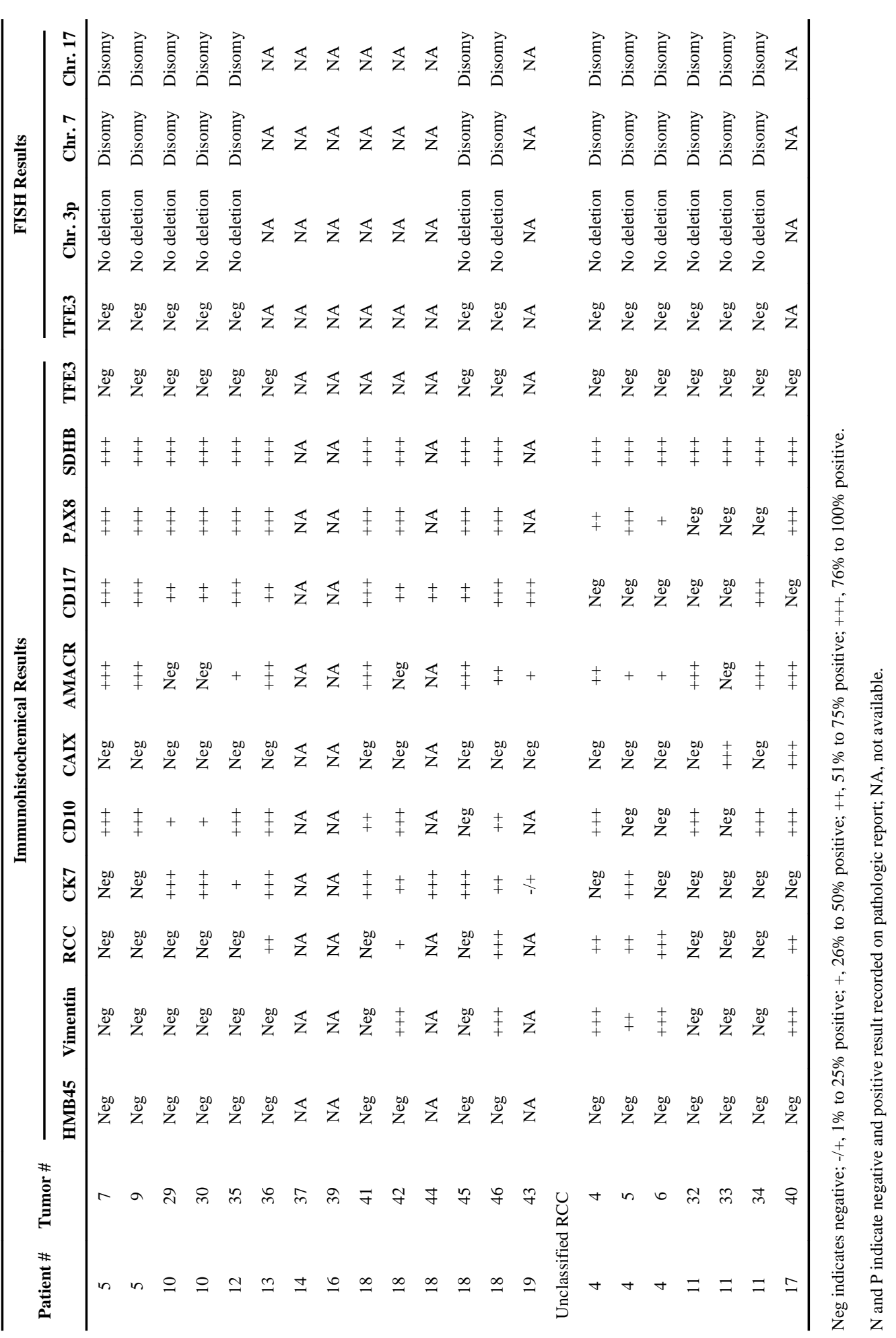


